\title{
A dynamic model of cylindrical plunge grinding process for chatter phenomena investigation
}

\author{
Pawet Lajmert ${ }^{1, *}$, Matgorzata Sikora $^{1}$, and Dariusz Ostrowski ${ }^{1}$ \\ ${ }^{1}$ Lodz University of Technology, Institute of Machine Tools and Production Engineering, Lodz, Poland
}

\begin{abstract}
In the paper, chatter vibrations in the cylindrical plunge grinding process are investigated. An improved model of the grinding process was developed which is able to simulate self-excited vibrations due to a regenerative effect on the workpiece and the grinding wheel surface. The model includes a finiteelement model of the workpiece, two degrees of freedom model of the grinding wheel headstock and a model of wheel-workpiece geometrical interferences. The model allows to studying the influence of different factors, i.e. workpiece and machine parameters as well as grinding conditions on the stability limit and a chatter vibration growth rate. At the end, simulation results are shown and compared with exemplified real grinding results.
\end{abstract}

\section{Introduction}

In grinding, all vibration processes are interrelated by physical and dynamic parameters of the machine tool, the workpiece and the grinding tool system [1]. Since grinding is a final operation, aimed at achieving high dimensional and shape accuracy of machined parts, vibrations should be minimised. It may be done through the selection of optimal grinding conditions at the design stage and next by monitoring of these vibrations to correct the grinding conditions or to decide about the grinding wheel redressing [2-6].

A chatter physical mechanism may be divided into two main categories, i.e. forced vibrations and selfexcited vibrations [7-11]. Forced vibrations originate from rotating machine tool elements, mainly unbalance of a rotating grinding wheel. In industrial practice, this kind of vibrations is eliminated by means of automatic wheel balancing systems. However, during the grinding, even a small unbalance of any machine tool element or eccentricity of the grinding wheel may induce other machine tool vibration modes, which are selectively amplified due to a regenerative effect [6-7]. The regenerative effect appears as waviness is worn into the grinding wheel or the workpiece. This waviness produces oscillatory forces which are transferred back to the process causing a gradual increase of the waviness amplitude until a vibration level is no longer acceptable from the point of view of the assumed part quality criteria. To recognize the regenerative mechanism, many models of plunge grinding process were created [12-16]. Basically, these models may be divided into analytical and time-domain models [14]. In literature, the most frequently used are the analytical models. These models are based on a model proposed by Snoeys at all [12], which contains blocks, representing two main closed loops, corresponding to the wheel and the workpiece regenerative effect. However, in these models, the machine tool dynamical structure is modelled as a simple transfer function block. Additionally, the wheelworkpiece geometrical interactions are treated in a simplified manner and modelled using analytical relationships. On the contrary, the time-domain models usually take these geometrical interactions into account $[13,15]$. Li and Shin [15] presented a time-domain model of the plunge grinding process which includes geometrical interactions between the wheel and workpiece to identify grinding chatter boundaries due to the regenerative effect on the workpiece. However, still structure dynamics is modelled using a modal system which must be first identified using modal analysis for each technological case. In [16] a model of the plunge grinding process was introduced to investigate the selfinterrupted grinding chatter. The workpiece is modelled as an Euler-Bernoulli beam and the grinding wheel as a spring-mass system. However, real wheel-workpiece geometrical interactions are not taken into consideration.

This paper presents an improved simulation model which takes into consideration a multi-degree of freedom model of grinding wheel headstock, a finite element model of the workpiece and a model of the wheelworkpiece geometrical interactions, including the wear mechanism of the grinding wheel. The model is useful in a simulation of grinding chatter development and prediction of stable grinding conditions. The proposed model does not require identification of modal parameters each time for different technological cases.

\section{Model description}

The model of the cylindrical plunge grinding process is composed of three components: a model of grinding

\footnotetext{
* Corresponding author: pawel.lajmert@p.p.lodz.pl
} 
wheel headstock, a model of workpiece transverse vibrations and a model of wheel-workpiece geometrical interactions.

\subsection{Model of grinding machine}

The model of the grinding process is illustrated in Figure 1. The grinding wheel headstock was modelled using a damped spring-mass system, representing grinding wheel having mass $m_{s}$, grinding wheel headstock having mass $m_{w}$ and a massless element, representing an infeed drive, which is responsible for a kinematic force input to the model. The position of this driving element is denoted by $x_{f}$. From the other side, on the grinding wheel two components of the grinding force act in normal $F_{n}$ and tangential $F_{t}$ directions.

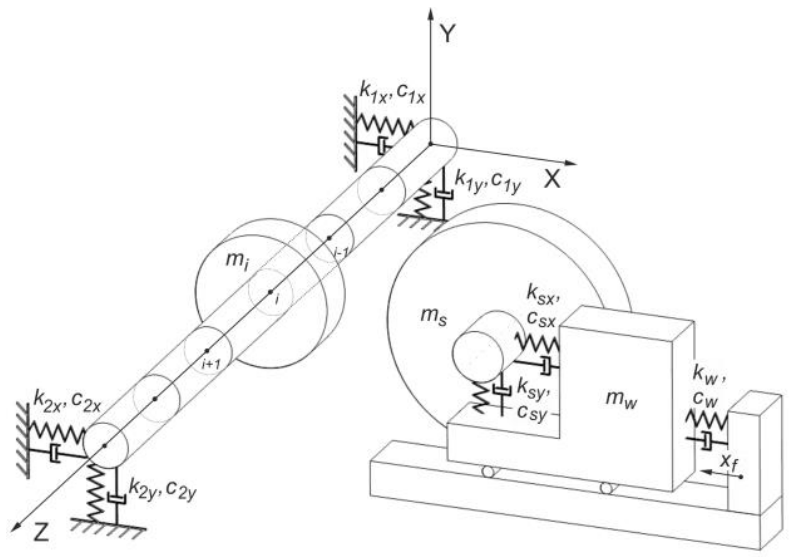

Fig. 1. Model of grinding wheel headstock and workpiece.

In the model, the mass representing the grinding wheel may displace in $\mathrm{X}$ and $\mathrm{Y}$ directions, while the wheel headstock only in $\mathrm{X}$ direction. The matrix equation of motion of this system may be expressed in the following form:

$$
\begin{aligned}
& {\left[\begin{array}{ccc}
m_{w} & 0 & 0 \\
0 & m_{s} & 0 \\
0 & 0 & m_{s}
\end{array}\right]\left[\begin{array}{l}
\ddot{x}_{w} \\
\ddot{x}_{s} \\
\ddot{y}_{s}
\end{array}\right]+\left[\begin{array}{ccc}
c_{s x} & -c_{s x} & 0 \\
-c_{s x} & c_{s x} & 0 \\
0 & 0 & c_{s y}
\end{array}\right]\left[\begin{array}{l}
\dot{x}_{w} \\
\dot{x}_{s} \\
\dot{y}_{s}
\end{array}\right]+} \\
& {\left[\begin{array}{ccc}
k_{s x} & -k_{s x} & 0 \\
-k_{s x} & k_{s x} & 0 \\
0 & 0 & k_{s x}
\end{array}\right]\left[\begin{array}{l}
x_{w} \\
x_{s} \\
y_{s}
\end{array}\right]=\left[\begin{array}{c}
c_{w}\left(\dot{x}_{f}-\dot{x}_{w}\right)+k_{w}\left(x_{f}-x_{w}\right) \\
-F_{n} \\
-F_{t}
\end{array}\right]}
\end{aligned}
$$

where $x_{f}, x_{w}, x_{s}, y_{s}$ are displacements of the infeed element, wheel headstock and the grinding wheel in $\mathrm{X}$ and $\mathrm{Y}$ direction.

The ground workpiece was discretized using the finite element method. A two-node beam elements with four degrees of freedom in a node (two translational and two rotational) were used. Far-right and far-left nodes of the workpiece model were supported using springs and dampers, which substitute the centres of workpiece headstock and a tailstock. A matrix equation of the workpiece may be expressed in the following form:

$$
\left[M_{g}\right] \ddot{q}+\left[C_{g}\right] \dot{q}+\left[K_{g}\right] q=F
$$

where $\boldsymbol{M}_{\boldsymbol{g}}, \boldsymbol{C}_{\boldsymbol{g}}, \boldsymbol{K}_{\boldsymbol{g}}$ are mass, damping and stiffness matrixes respectively, $\boldsymbol{q}$ is a vector of generalized displacements and $\boldsymbol{F}$ is a force vector containing normal and tangential force components spread between two nodes where the force is applied. In equation (2) the damping matrix is a linear combination of the mass and stiffness matrixes. For both models. adequate coefficients were chosen based on modal experiments and the peak picking method.

\subsection{Model of geometrical interactions}

In the model of wheel-workpiece geometrical interactions the surface of the grinding wheel and the workpiece is discretized using equally spaced supporting points as shown in Figure 2.

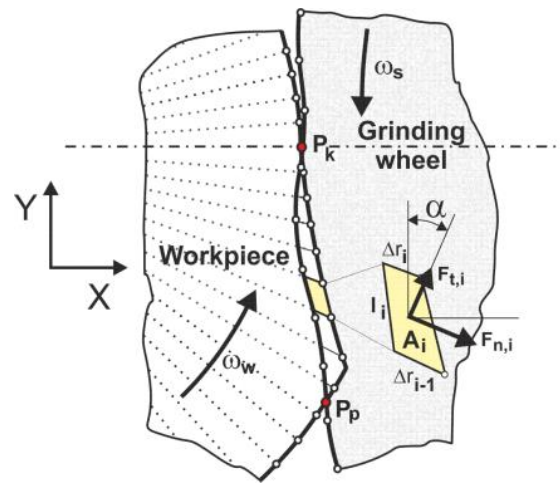

Fig. 2. Grinding wheel and workpiece geometrical interactions.

Force components are calculated based on discretized cross-section area of workpiece and the grinding wheel. For each elementary cross-section element $A_{i}$ normal and tangential force components are calculated. The resultant force components may be given in the following form:

$$
\left\{\begin{array}{l}
F_{n}=\sum_{i}\left(F_{n, i} \cos \alpha+F_{t, i} \sin \alpha\right) \\
F_{t}=\sum_{i}\left(-F_{n, i} \sin \alpha+F_{t, i} \cos \alpha\right)
\end{array}\right.
$$

The simulation algorithm includes the following steps:

- displacement and rotation of the workpiece and the grinding wheel resulting from their rotational velocities and infeed velocity of the wheel,

- determination of the force components based on crosssection area of the wheel and the workpiece,

- displacement of the grinding wheel and the workpiece resulting from the dynamical models and estimated force components,

- movement of the supporting points on the grinding wheel due to the wear of abrasive grains,

- movement of the supporting points of the workpiece based on current contact conditions of the wheel and workpiece.

\section{Measurement test stand}

To verify the usefulness of the proposed model, experimental research has been carried out for different 
grinding conditions on cylindrical grinding machines [17-18]. These machines were equipped with sensors for the measurement of grinding force components and vibrations. Force components were measured using Kistler piezoelectric sensors mounted between the body of the wheel headstock and the housing of the wheel spindle. Vibration signals were acquired using piezoelectric sensors mounted on the grinding wheel headstock and the tailstock centre. Signals from these sensors were used to detect unstable grinding conditions. During the experiments, the rings were ground made of $34 \mathrm{CrAl6C}$ steel hardened to $52 \mathrm{HRC}$ of width $10-20 \mathrm{~mm}$ mounted on a shafts of different lengths (a rigid and flexible system). A $38 \mathrm{~A} 60 \mathrm{~K} 5 \mathrm{~V}$ aluminum oxide grinding wheel was used. After grinding tests, the workpiece and grinding wheel shape were measured using a specially designed device, equipped with a laser triangulation sensor, see Figure 3.

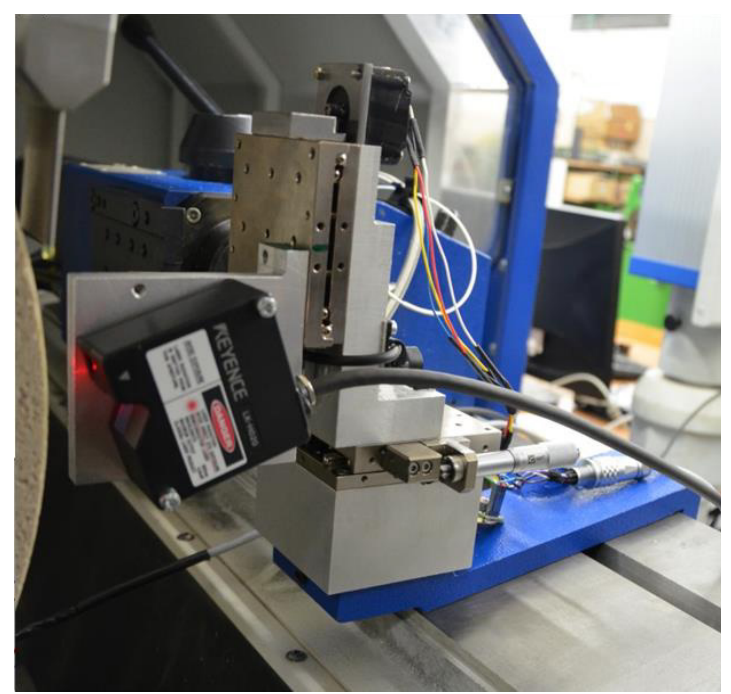

Fig. 3. General view of grinding wheel shape measurement device.

\section{Simulation results}

Based on the described grinding process model, a simulation software was created which allows determining a static and dynamic course of normal and tangential force components, displacement and acceleration of any element of the system and the generated shape of the workpiece and the grinding wheel due to the wheel wear.

First, a simulation of workpiece regenerative effect was conducted. During the exemplified simulation, workpiece peripheral speed was changed at time 20 sek from $n_{w}=1 \mathrm{rev} / \mathrm{s}$ (stable conditions) to $9 \mathrm{rev} / \mathrm{s}$ which corresponds to the unstable region of grinding. A course of the normal force component is shown in Figure 4. After the speed change, the amplitude of normal force component increases gradually and after a certain time, the workpiece losses the contact with the grinding wheel which bears the evidence of process instability. It is observable that this kind of chatter develops relatively fast.

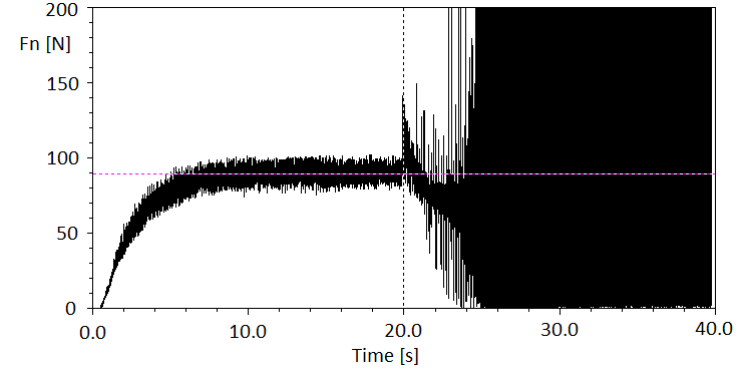

Fig. 4. Course of normal force component during the change in workpiece peripheral speed from $n_{w}=1$ to $9 \mathrm{rev} / \mathrm{s}\left(v_{f}=10 \mu \mathrm{m} / \mathrm{s}\right.$, $b=15 \mathrm{~mm}$ ).

In Figure 5 a corresponding spectrum of normal force component is shown. The dominant frequency amplitude is about $710 \mathrm{~Hz}$. This frequency multiplied by workpiece rotational speed should produce about 78 waves on the workpiece periphery. In Figure 6, the resultant workpiece shape and waviness distribution are presented. As it may be observed, the number of obtained waves on the workpiece periphery closely corresponds to the anticipated number of waves.

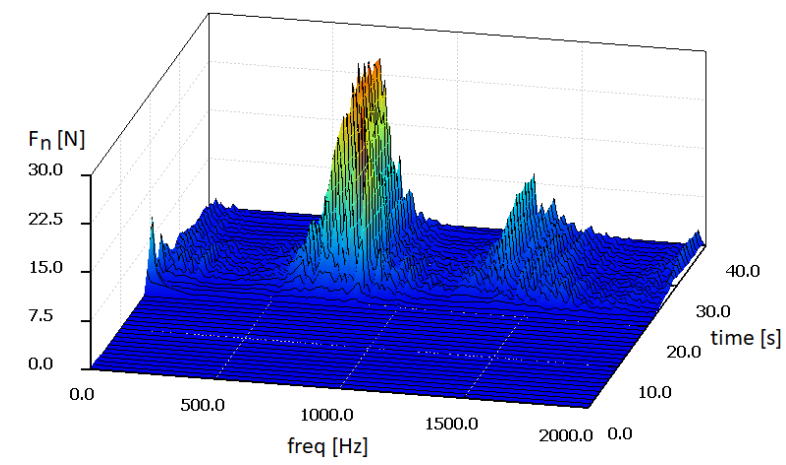

Fig. 5. Specturm of normal force component during the simulation.
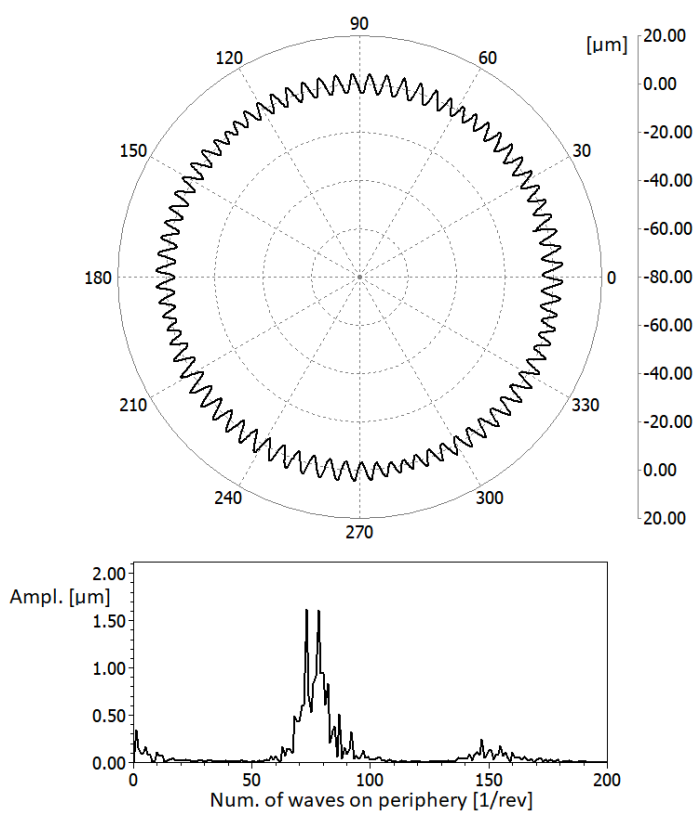

Fig. 6. Workpiece shape and wavines distribution after grinding in unstable conditions. 
The model was also used to predict the stable grinding region and to compare with experimental results. Simulation and experimental tests were done for different specific material removal rates $Q^{\prime}{ }_{w}$ and workpiece peripheral speeds $v_{w}$. The identified stable region obtained during the simulation and experiment (red line) is shown in Figure 7. Additionally, in Figure 7, restrictions due to the workpiece thermal damage are shown. As it may be seen, simulation results well match the experimental ones.

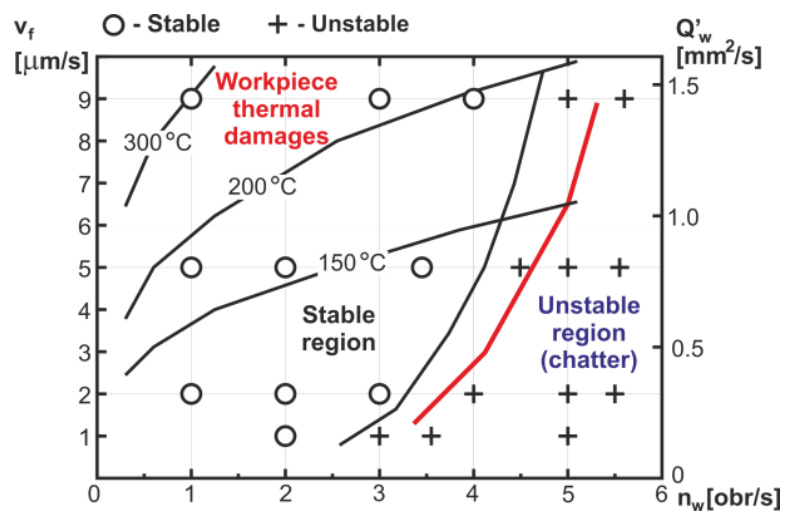

Fig. 7. The identified stable grinding region obtained during simulation and experiment (red line).

The developed simulation program allows also to investigate the regenerative effect on the grinding wheel surface and predict the resultant waviness on the ground workpiece. In Figure 8, a comparison of grinding wheel shapes at the end of wheel life obtained during the experiment and simulation are presented. The obtained shapes are quite similar but the shape obtained during the experiment is more irregular.

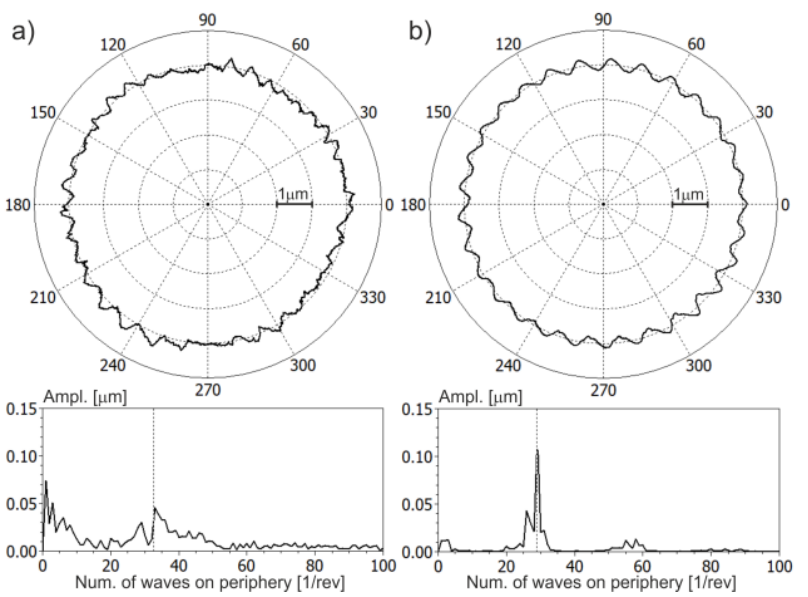

Fig. 8. Grinding wheel shapes and waviness amplitude distribution for a worn girnding wheel obtained during: a) experiment and b) simulation.

\section{Conclusions}

In this paper, a time domain model of cylindrical plunge grinding process is presented, which combines finite element model of workpiece deflection and two degrees of freedom model of grinding wheel headstock. The nonlinear effect caused by the wheel workpiece geometrical interactions has been taken into account. Using the developed model it is possible to find the optimal working conditions in respect to waviness development on the workpiece. Based on diagrams of stable grinding conditions, the correct operating kinematic parameters can be established for the following grinding phases what should advantageously affect the final part quality parameters and increase machining efficiency. Furthermore, the model allows studying the influence of grinding conditions, a machine tool and workpiece physical and dynamical parameters on grinding force and vibrations growth due to the wheel regenerative effect. Using the proposed model, it will be also possible to develop more conducive, diagnostic systems, necessary to identify process instability and to develop effective methods of chatter suppression.

\section{References}

1. M. Weck, K. H. Schiefer, Ann. of the CIRP 38/1, 281-285 (1979)

2. B. Kruszynski, P. Lajmert, Ann. of the CIRP 54/1, 305-308 (2005)

3. B. Kruszynski, P. Lajmert, Proc. Inst. Mech. Eng., Part B: J. Eng. Manuf. 220, 355-363 (2006)

4. L. Zylka, Babiarz R., J. of Mechanical Science and Technolgy 31/9, 4411-4417 (2017)

5. L. Zylka, J. Burek, D. Mazur, Adv. in Production Engineerign \& Management 12, 221-232 (2017)

6. P. Lajmert, M. Sikora, B. Kruszynski, D. Ostrowski, Lecture Notes in Mech. Eng, Adv. in Manufacturing, 707-716 (2018)

7. I. Inasaki, B. Karpuschewski, H.-S. Lee, Ann. of the CIRP 50/2, 515-534 (2001)

8. P. Wolszczak, K. Lygas, G. Litak, Adv. In Sci. and Tech. Research Journal 11/1, 96-103 (2017)

9. Y. Altintas, M. Weck, Ann. of the CIRP 53/2, 619642 (2004)

10. G. Litak, R. Rusinek, K. Kecik, A. Rysak, A. Syta, Discontinuity and complexity in nonlinear physical systems, Springer 359-367 (2014)

11. K. Kęcik, R. Rusinek, J. Warmiński, Int. J. of Bifurcation and Chaos 21/10, 2943-2954 (2011)

12. R. Snoyes, D. Brown, Proc. $10^{\text {th }}$ Int. Machine Tool Des. and Res. Conf., Manchester, 325-348 (1969)

13. M. Weck, N. Hennes, A. Schulz, Ann. of the CIRP 50/1, 213-216 (2001)

14. J. Biera, J. Vinolas, F.J. Nieto, Int. J. Mach. Tools and Manufact. 37/11, 1555-1572 (1997)

15. H. Li, Y.C. Shin, Int. J. of Machine Tools \& Manufacture 47, 1563-1572 (2007)

16. Y. Yan, J. Xu, M. Wiercigroch, Meccanica 51, 3185-3202 (2016)

17. P. Lajmert, P. Leżański, Archives of Mechanical Technology and Automation 33/3, 3-15 (2013)

18. P. Lajmert, D. Ostrowski, M. Sikora, B. Kruszyński, Mechanic 8/9, 195-202 (2014) 